\title{
HERMENÊUTICA JURÍDICA E A QUESTÃO DA TEXTURA ABERTA
}

LEGAL HERMENEUTICS AND THE QUESTION OF THE OPEN TEXTURE

José Maria Arruda de Andrade*

\begin{abstract}
Resumo:
O presente artigo pretende trabalhar a utilização de certas expressões relativizantes no bojo de uma hermenêutica jurídica tradicional, que acaba por comprometer a própria base teórica adotada, já que não há uma proposta de sua superação. Nesse sentido, a referência a termos como (i) a presença de uma "carga subjetiva" na interpretação de textos normativos jurídicos e (ii) a ambigüidade e a vagueza dos conceitos jurídicos interpretados parecem atuar mais como meras flexibilizações de um ideal absolutista hermenêutico (representado pelas teorias tradicionais) do que como uma resposta para a crise daquelas teorias, advinda de diversas frentes de teorias relativistas.

Palavras-chave: Hermenêutica. Filosofia da Linguagem. Ludwig Wittgenstein. Friedrich Waismann. Textura aberta. Ambigüidade. Vagueza. Conceitos legais.
\end{abstract}

\begin{abstract}
:
The present article intends to work the application of a certain expressions related to the basis of traditional hermeneutic that ends up compromising the own theoretical bases adopted since there is not a proposal to overcome it. In this manner the reference to terms such as (i) the presence of a "subjective load" in legal normative texts and (ii) the ambiguity and the vagueness of legal concepts interpreted seem to act more as simple flexibilities of an hermeneutic absolutistic idea (represented by traditional theories) than an answer to the crisis derived from those views theories originated from several relativistic theories.
\end{abstract}

Keywords: Hermeneutic. Philosophy of language. Ludwig Wittgenstein. Friedrich Waismann. Open texture. Ambiguity. Vagueness. Legal concepts.

\section{Introdução}

$\mathrm{O}$ estudo da hermenêutica jurídica mais recente demonstra um certo afastamento de algumas características identificadas como tradicionais, sobretudo o caráter absoluto da possibilidade de descoberta de um sentido e alcance preexistentes do dispositivo normativo interpretado.

Em outros termos, encontra-se com facilidade uma certa flexibilização da afirmação da capacidade de se achar a resposta correta e única ao significado de um texto objeto da análise.

Professor Doutor do Departamento de Direito Econômico-Financeiro da Faculdade de Direito da Universidade de São Paulo. 
Por outro lado, sobretudo diante da preocupação com a segurança jurídica, essa flexibilização não vem acompanhada de uma crítica ao modelo cognitivo inerente aos construtos hermenêuticos jurídicos tradicionais, baseados (i) na descoberta de sentido, (ii) na relação sujeito-objeto e (iii) na propriedade de o texto representar realidades/sentidos. Abaixo analisaremos algumas flexibilizações comuns nos estudos hermenêuticos.

2. A carga subjetiva na interpretação

Comumente alega-se o elemento volitivo como flexibilizador da "exatidão" das respostas interpretativas. Note-se, aqui tem-se algo bem distinto do que Hans Kelsen afirmara: "[...] a interpretação cognoscitiva (obtida por uma operação de conhecimento) do Direito a aplicar combina-se com um acto de vontade em que o órgão aplicador efectua uma escolha entre as possibilidades reveladas através daquela mesma interpretação cognoscitiva" [1984:470].

Para Kelsen, a própria interpretação/aplicação do Direito estaria fora do que ele denominara como Ciência do Direito. Comporia, isso sim, parte da designada política do Direito [1984:469].

A afirmação desse jurista austríaco, tão incômoda para aqueles que o liam como um mero defensor da pureza do Direito, e não como um pensador neokantiano que pretendera aplicar os pressupostos dessa corrente na ciência jurídica, propondo um corte epistemológico (opção científica) e não uma "limpeza da realidade", representa um marco nos estudos jurídicos. ${ }^{1}$

Porém, neste artigo, a referência será àquelas flexibilizações meramente apaziguadoras, que misturam "busca de sentido", "conteúdo preexistente do texto da norma" com "elementos volitivos".

Esse tipo de enfoque altera as características mais tradicionais da hermenêutica jurídica, mas acabam por nada resolver, já que o elemento volitivo parece

\footnotetext{
Interessante citar, nesse momento, Eros Grau: "Fui um crítico exacerbado de Kelsen, ousadamente, até o momento em que verifiquei que há dois Kelsen: o verdadeiro, crítico formal do Direito, e aquele em que o transformam alguns dos seus leitores. Percebi, então, que minhas críticas a Kelsen deveriam ser não a ele destinadas, porém a alguns supostos kelsenianos, aqueles que fazem com que a teoria de Kelsen seja importante não pelo que estuda, mas sim pelo que deixa de estudar.

$[\ldots]$

[...] Daí porque os kelsenianos hão de se preocupar única e exclusivamente com a estrutura lógica das normas jurídicas, sem cogitar de sua interpretação/aplicação - tais cogitações estão para além da teoria pura. Para que tomem conhecimento do mundo no qual se vive o Direito são obrigados a descer do seu altiplano teórico, para se porem a braços com a Dogmática" [2002b:32-33].
} 
apenas flexibilizar a exatidão de resultados pretendida pela teoria tradicionalista, sem, contudo, justificar a manutenção dos pressupostos herdados daquela visão tradicional.

Ainda em outros termos, critica-se aqui a tentativa de se evitar a adoção tradicional da definição do que é interpretação (ou seja, seu caráter absoluto de busca do sentido correto e justo), adotando-se, para isso, flexibilizações sem atentar ou assumir o fato de que elas destróem o próprio edifício da definição anterior.

A afirmação clássica, ainda que hipotética, dos autores é: “a interpretação é a busca do sentido e alcance da norma. Porém, muitas vezes, alguns problemas podem surgir, tendo em vista que não há como se eliminar a carga subjetiva do intérprete. Diante disso, torna-se necessário seguir os elementos da hermenêutica: gramática, história, sistemática e teleologia etc."

No Direito, muitas vezes, os próprios autores que conceituam a interpretação como busca de um dado prévio (que é o sentido, o conteúdo e o alcance que serão definidos, posteriormente, de forma correta) reconhecem que a utilização desses métodos poderá resultar em mais de uma opção de resultado.

Esse fator, às vezes, é justificado como humanização do Direito ou mesmo como obstáculos da aplicação que, mediante outros elementos válidos, juridicamente, acabarão por determinar a solução correta.

Em último caso, como aparece nos construtos teóricos mais recentes, identifica-se a fragilidade da tarefa da determinação do sentido correto, mas não se questionam os pressupostos da teorização. No máximo, apresentam-se flexibilizações da capacidade dos métodos de interpretação, da idéia de completude do sistema etc., mas não a fragilidade da própria atividade "racional/mental" de determinação do sentido de um texto, seja ele normativo ou-não.

Perceba-se, a censura aqui vai à mera citação da "carga subjetiva", como um elemento existente, porém marginal. Ora, a tal "carga subjetiva", ou a "humanização do Direito", é simplesmente a interpretação/aplicação/concreção do Direito (texto normativo). Não é uma mera adaptação, não é uma mera atualização, é a realização, é o funcionamento, é, em termos müllerianos, a própria metódica jurídica. ${ }^{2}$

\footnotetext{
2 Friedrich Müller apresenta a seguinte noção de metódica jurídica: "Como designação de uma concepção global sistematicamente reflexionante dos modos de trabalho do Direito (constitucional), a 'metódica' no sentido aqui usado é o conceito abrangente de 'hermenêutica', 'interpretação', 'métodos de interpretação [Auslegung]' e 'metodologia' ['Methodenlehre'].

[...] Assim a 'metódica' no sentido aqui apresentado abrange em princípio todas as modalidades de trabalho da concretização da norma e da realização do Direito, mesmo à medida que elas transcendem - como análise dos âmbitos das normas, como o papel dos argumentos de teoria do Estado, teoria do Direito e teoria constitucional, como conteúdos dogmáticos, elementos de técnica de solução e elementos de política jurídica, bem como constitucional - os métodos de interpretação [Auslegung] ou interpretação [Interpretation] no sentido tradicionalmente restringido [2000:22].
} 


\section{Ambigüidades e vaguezas (textura aberta) do texto normativo}

Outra comum relativização dos princípios tradicionais da hermenêutica jurídica é o apontamento de ambigüidades e de vaguezas dos termos jurídicos e da linguagem ordinária que os forma.

Com relação à ambigüidade, tem-se a possibilidade de um texto expressar mais de um sentido, seja diante de uma homonomia acidental, seja diante de uma "ambigüidade de processo-produto", ${ }^{3}$ seja, ainda, diante de divergência entre seu sentido técnico ou ordinário. [Santiago Nino, 1999:261]. ${ }^{4}$

Pode ocorrer a ambigüidade também em razão de problemas com a conexão sintática dos termos (conectores como "e", "ou”, por exemplo).

Outro fator relativizante da hermenêutica jurídica é a imprecisão ou a vagueza das palavras, seja diante de um dos termos do texto, seja diante da combinação deles que, somados, acabam por tornar a sentença vaga.

Costuma-se relatar que, de um lado, há objetos cuja relação com uma palavra não parece apresentar maiores problemas, tendo em vista possuírem propriedades tais que afastariam dúvidas desconcertantes. De outro, há outros objetos que não oferecem dúvidas quanto à sua falta de relação com a mesma palavra. Por fim, haveria aquela classe cuja identidade com a determinada palavra aqui aludida restaria duvidosa.

Daí a consideração de Genaro Carrió:

Respecto de todas ellas vale la siguiente metáfora esclarecedora. Hay un foco de intensidad luminosa donde se agrupam los ejemplos típicos, aquellos frente a los cuales no se duda que la palabra es apicable. Hay una mediata zona de oscuridad circundante donde caen todos los casos en los que no se duda que no lo es. El tránsito de una zona a otra es gradual; entre la total luminosidad y la oscuridad total hay una zona de penumbra sin límites precisos. Paradójicamente ella no empieza ni termina en ninguna parte, y sin embargo existe. Las palabras que diariamente usamos para aludir al mundo en que vivimos y a nosotros mismos llevan consigo esa imprecisa aura de imprecisión.

$[\ldots]$

Esta característica de vaguedad potencial que los lenguajes naturales necesariamente exhíben ha sido llamada por

\footnotetext{
3 Assevera Santiago Nino: “Así ocurre con la llamada ‘ambigüidad de processo-producto', que se da cuando uno de los significados de la palabra se refiere a una actividad o proceso. Es lo que acaece con palabras como 'trabajo', 'ciencia', 'construcción', 'pintura'. Si alguien dice 'me ancanta la pintura', puede dudarse de si lo que le gusta es pintar él o contemplar cuadros" [1999:261].

4 Esse capítulo da obra de Santiago Nino é diretamente influenciado pelo livro de Genaro Carrió [1979]. Sobre ambigüidade, ver [Carrió, 1979:29-31].
} 
Waismann 'la textura abierta del lenguaje'. Carnap alude al mismo fenómeno cuando habla de 'vaguedad intensional'. [1979:33-35].

E, mais adiante:

Las palabras que aperecem en las normas jurídicas para aludir a hechos, sucesos o actividades humanas, y proporcionar pautas o criterios para guiar o juzgar estas últimas, tienen, pues, una zona de penumbra, es decir, son actual o potencialmente vagas. [1979:55].

Conforme visto, alega-se, no capítulo referente à vagueza potencial dos textos normativos, a "textura aberta" das palavras objeto de interpretação.

Genaro Carrió, muitas vezes lembrado quando se trata de explorar o tema da vagueza da norma (das palavras que a compõem), utiliza uma seqüência de estudiosos para fundamentar seus apontamentos: Herbert Hart $^{5}$ e Alfred Ross, na seara jusfilosófica, e Friedrich Waismann e Ludwig Wittgenstein, na filosofia da linguagem.

Como se trata de um tema freqüentemente abordado, no quesito de relativização das concepções de uma hermenêutica tradicional, vale apontar algumas de suas características.

Após a repercussão das obras de Gottlob Frege (1848-1925) e de Bertrand Russell (1872-1970), que buscavam o desenvolvimento da lógica formal e da filosofia da matemática, muitos estudiosos voltaram sua atenção à possibilidade de se estabelecer um novo rigor na elaboração da linguagem científica.

Além disso, o ambiente intelectual austríaco, resistente ao idealismo de Kant e sensível a um realismo científico positivista, fomentou a reunião, em torno de Moritz Schlick (1882-1936), de um grupo de pensadores, entre eles Otto Neurath (1882-1945), Friedrich Waismann (1896-1959) e Rudolf Carnap (1891-1970), que se auto-denominavam Círculo de Viena [Wiener Kreiss]. Muitos os designam, ainda, como neopositivistas ou positivistas lógicos. ${ }^{6}$

Sobre a influência direta de Waismann e indireta de Wittgenstein sobre a obra de Herbert Hart, sobretudo em seus primeiros escritos (como "The Ascription of Responsability and Rights" de 1948-1949), ver Bix [1993:735] e [2000:205-211].

6 Cf. Granger [s/d-a:83-84] e Granger [s/d-b:87]. Sobre os três princípios maiores do Círculo de Viena e da Sociedade para Uma Filosofia Empírica [Gesellschaft für empirische Philosophie], de Berlim, e com a qual o Círculo decidira colaborar, ver Granger [s/d-a:84-85], cuja explicação desses princípios pode ser resumida nas seguintes proposições: $(i)$ a ciência deve poder ser unificada na sua linguagem e nos fatos que a fundam; (ii) a filosofia reduz-se à elucidação das proposições científicas, por meio da verificação dessas proposições e do uso do simbolismo lógico de Frege e Russel, (iii) o sucesso de uma tal filosofia anuncia o fim da metafísica. Sobre as concepções básicas de Wittgenstein assumidas pelos pensadores do Círculo de Viena ("sua interpretação da lógica e das proposições lógicas"; "sua teoria das proposições empíricas" e "sua definição de filosofia"), ver Rudolf Haller [1990:29-33]. 
Pois bem, após uma aproximação de Moritz Schlick em 1927, e mesmo tendo Ludwig Wittgenstein (1889-1951) se negado a participar das reuniões do Círculo de Viena, no verão desse ano ele passa a ter reuniões com Schlick e com alguns membros por este selecionados do Círculo de Viena (Rudolf Carnap, Friedrich Waismann, por exemplo) [Monk, 1995:224-225].

Muito embora tenha ficado provado para alguns desses participantes, sobretudo para Rudolf Carnap, que Wittgenstein não era o positivista que eles apreenderam do Tractatus Logico-Philosophicus, vários temas da lógica e da matemática foram tratados nessas reuniões [Monk, 1995:226]. ${ }^{7}$

Após essa primeira série de encontros e do retorno de Wittgenstein a Cambridge e à filosofia que ele abandonara, os membros do Círculo de Viena publicaram

Sobre o tema verificação, vale lembrar o trecho do Tractatus sempre lembrado pelos pensadores do Círculo de Viena: "4.024 Entender uma proposição é saber o que o caso é quando ela é verdadeira [Einen Satz verstehen, heisst, wissen was der Fall ist, wenn er wahr ist]...”.

O princípio verificacionista foi primeiramente adotado pelo Círculo, muito embora seus pensadores o atribuam a Wittgenstein [TLP:4.024]. Ao que parece, a transição entre a afirmação acima citada e a técnica verificacionista teria sido passada por Wittgenstein a Waismann, em uma série de encontros para abordar o Tractatus. Essa visão, que podemos denominar como semântico-realista, posteriormente foi abandonada por Wittgenstein. Sobre o verificacionismo, ver, entre outros, Glock [1998:367-370].

Sobre a filosofia austríaca e a sua tendência ao empirismo, em contraposição à tradição alemã, idealista, ver Haller [1990:17-29].

Sobre a resistência dos membros do Círculo com o termo "positivismo", devido à sua ligação histórica com Comte, ver Haller [1990:47-48]. Para um quadro geral das características dos construtos dos pensadores desse grupo, verificar Haller [1990:47-54].

7 Apesar de extensa, a citação que aqui segue consegue exprimir bem o intento dos positivistas lógicos e a inspiração que foi buscada em Wittgenstein: "Se a empresa enciclopedista dos neopositivistas assenta em definitivo numa unificação da linguagem [para Carnap e Neurath, esta linguagem é a da física], é porque a função lógica da expressão lingüística é para eles essencial.

É, antes de mais, do Wittgenstein do Tractatus logico-philosophicus (1921) que eles recebem a herança sobre este ponto. Para este filósofo, a linguagem é a imagem do mundo e a ciência não é mais do que o conjunto das proposições que a descrevem. Cada uma destas proposições é a imagem de um facto, que se analisa por ligações entre factos elementares, ou estados de coisas, a cada um dos quais corresponde uma proposição elementar que é a sua imagem e que consiste na associação de um predicado e dos nomes que se lhe referem. Deste modo, a lógica, ou seja o aspecto a priori do conhecimento científico, reduz-se ao conjunto dos constrangimentos que regulam o uso das ligações proposicionais e o uso dos predicados. A lógica não é mais do que uma gramática da língua que descreve o mundo.

Os neopositivistas reterão daí que a análise da linguagem é a única via de acesso à lógica e que o aparato da lógica simbólica é o instrumento que o filósofo deve aplicar à elucidação de todo o enunciado, qualquer que ele seja.

A importância desta nova lógica para os neopositivistas é tal, que a associação do formalismo lingüístico e do empirismo constitui uma das suas novações fundamentais" [Granger, s/d-b:89-90].

Sobre a questão do uso da linguagem fisicalista, acima aludida por Granger, Haller [1990:48-49] assinalará a reação de Wittgenstein a um artigo de Carnap ("A Linguagem Fisicalista como Linguagem Universal das Ciências" - Die physikalische Sprache als Universalsprache der Wissenschaften). Wittgenstein escreveu duas cartas em 1932, uma a Carnap e outra a Schlick, acusando o primeiro de plágio, sobretudo pela referência ao fisicalismo e pela adoção de sua visão de hipótese.

Sobre esse último ponto, adiante se verá que uma das origens do termo "textura aberta", atribuído a Waismann, vem da noção de hypothesis e semelhanças de família [Struchiner, 2002:23-32]. 
um manifesto com as posições antimetafísicas do grupo, ${ }^{8}$ no qual foi anunciada uma obra de Waismann, introdutória ao Tractatus de Wittgenstein [Monk, 1995:259-2s60].

A obra acabou não sendo publicada, mas Waismann teve uma série de encontros com Wittgenstein, de início para compreender melhor o Tractatus e, depois, para entender as razões pelas quais o Autor pretendia refutá-lo [Haller, 1990:42-43].

No âmbito do Círculo de Viena, Schlick e, sobretudo Waismann, eram vistos como expositores e, de certa forma, os defensores do ponto de vista de Wittgenstein, pontos esses que eram exaustivamente ali tratados [Haller, 1990:43].

Daí que muitos escritos de Waismann apresentam várias características das idéias de Wittgenstein. Uma construção de Waismann bastante citada é a noção de "porosität der Begriffe", que, por sugestão de Kneale, foi traduzida como "open texture"; logo, textura aberta da linguagem [Struchiner, 2002:11].

Essa idéia está muito próxima de algumas observações de Wittgenstein, sobretudo sua idéia de semelhanças de família e de hipótese. Não é o caso de analisar esses construtos aqui. Neste momento, adiantamos tão-somente que o enfoque adotado por Wittgenstein na idéia de semelhanças de família é distinto daquele adotado por Waismann, ponto que abordaremos sucintamente no final deste artigo.

Do ponto de vista jurídico, Herbert Hart constata, a partir de suas já citadas premissas teóricas, que há situações de fato simples nas quais as expressões gerais são facilmente empregadas, existindo, todavia, aquelas situações nas quais a facilidade não se faz presente. As situações fáticas não se apresentam ao aplicador previamente catalogadas, nem as regras aplicadas avançam, reclamando seus casos de utilização [1986:139].

Tampouco podem os cânones hermenêuticos eliminar essas incertezas (muito embora as diminua), tendo em vista serem, eles próprios, "regras gerais sobre o uso da linguagem e utilizam termos gerais que, eles próprios, exigem interpretação" [Hart, 1986:139]. ${ }^{9}$

\footnotetext{
8 Die Wissenschaftliche Weltausffassung: der Wiener Kreis [A concepção científica do mundo: Círculo de Viena], de 1929.

9 Mais adiante, afirma o autor: “A textura aberta do Direito significa que há, na verdade, áreas de conduta em que muitas coisas devem ser deixadas para serem desenvolvidas pelos tribunais ou pelos funcionários, os quais determinam o equilíbrio, à luz das circunstâncias, entre interesses conflitantes que variam em peso, de caso para caso. Seja como for, a vida do Direito traduz-se em larga medida na orientação, quer das autoridades, quer dos indivíduos privados, através de regras determinadas que, diferentemente das aplicações de padrões variáveis, não exigem deles uma apreciação nova de caso para caso. Este facto saliente da vida social continua a ser verdadeiro, mesmo que possam surgir incertezas relativamente à aplicabilidade de qualquer regra (quer escrita, quer comunicada por precedente) a um caso concreto. Aqui, na franja das regras e no campo deixado em aberto pela teoria dos precedentes, os tribunais preenchem uma função criadora de regras que os organismos administrativos executam de forma centralizada na elaboração de padrões variáveis [...] [Hart, 1986:148-149]".
} 
A questão aqui gera um problema. Se há regras vagas (devido à textura aberta de seus termos), como procederá o intérprete dessas regras? Na terminologia de Hart, será o caso de uma decisão discricionária.

Daí surge uma polêmica abordada por Hart e outros juristas, como Carrió [1979:62-72] e Norberto Bobbio [1995:142-144], entre os formalistas/positivistas e os realistas.

Os primeiros negam qualquer incompletude do ordenamento, qualquer incapacidade de dedução de decisões por meio de recursos lógicos. Ou seja, tanto os casos de penumbra, quanto os claros seriam iguais e facilmente solucionáveis com os recursos lógicos disponíveis. ${ }^{10}$ No segundo caso, os realistas entenderiam que, em ambos os casos, o enfoque deveria recair sobre a aplicação dos textos, tendo em vista que as características dele (potencialmente vagos, imprecisos) não justificariam a atenção do pesquisador. ${ }^{11}$

Tem-se aqui a difícil tarefa daqueles autores que, constatando a ausência de possibilidade de univocidade de sentido das regras interpretadas (e, não-só por isso, tendo que abandonar o formalismo/positivismo), têm que reformular a teoria jurídica sem, contudo, cair em outros extremos, seja no realismo jurídico, seja na livre criação do Direito. Em outros termos, sem negar a importância das regras ${ }^{12}$ e sem defender a idéia de que toda aplicação seja uma adjudicação (citando a nomenclatura de Carrió) ou uma discricionariedade (valendo-se da expressão de Hart).

Daí a necessidade deles (Carrió, por exemplo) em afirmar que nem sempre se está diante de regras imprecisas e vagas e que, portanto, a atitude criadora do intérprete deve ser limitada àqueles casos de penumbra.

\footnotetext{
${ }^{10}$ Sobre uso de recursos lógicos na Jurisprudência dos conceitos [Begriffsjurisprudenz] ou Pandectística [Pandektenwissenschaft] e sua influência da formação de diversos setores dogmáticos do Direito, como o Direito Tributário, ver Andrade [2006:46-52].

${ }^{11}$ Nos dizeres de Hart, "Argumentar desse modo é ignorar o que as regras efectivamente são em qualquer esfera da vida real. Sugere que estamos confrontados com o dilema: $<<$ ou as regras são o que seriam no paraíso de um formalista e então vinculam tanto como grilhões; ou não há regras, mas só decisões ou padrões de comportamento susceptíveis de predição $\gg$. Contudo, isto é sem dúvida um falso dilema" [...] [1986:152]. Não por acaso, no mesmo sentido Wittgenstein já declarara: "Mas então o emprego da palavra não está regulamentado." Ele [o emprego da palavra] não está [regulamentado] inteiramente por regras; mas também não há nenhuma regra no tênis que prescreva até que altura é permitido lançar a bola nem com quanta força; mas o tênis é um jogo e também tem regras" [PhU, 79:§68] [>>Aber dann ist ja die Anwendung des Wortes nicht geregelt; das 'Spiel', welches wir mit ihm spielen, ist nicht geregelt $<<$ - Es ist nicht überall von Regeln begrenzt; aber es gibt ja auch keine Regel dafür z.B., wie hoch man im Tennis den Ball werfen darf,oder wie stark, aber Tennis ist doch ein Spiel und es hat auch Regeln].

${ }^{12}$ Cf. Carrió [1979:72] e Hart [1986:149-152].
} 
Essa polêmica, não entre realismo ou formalismo, mas entre uma interpretação mecanicista, meramente dedutiva, e outra, baseada na concreção de textos normativos (formação da norma-decisão), está presente em vários debates contemporâneos. ${ }^{13}$

Nesse ponto, vale tecer algumas considerações. A primeira é o enfoque dado à questão da ambigüidade e da vagueza (textura aberta) do texto normativo como elemento flexibilizador de uma hermenêutica aqui denominada de tradicional. A segunda diz respeito à forma como trabalhamos a textura aberta dos textos.

Até agora, esses tópicos (carga subjetiva e ambigüidade/vagueza) foram aqui apresentados no sentido de criticar uma atitude comum no trato da matéria hermenêutica, qual seja, a de citá-los a fim de fugir do absolutismo da posição formalista/positivista, sem, contudo, desfiliar-se de seus pressupostos metodológicos.

Correndo o risco de repetição desnecessária, vale lembrar: o presente artigo critica a atitude de definir a interpretação como a "descoberta" de um sentido preexistente, por meio das pautas hermenêuticas tradicionais, seguida da afirmação de que (i) há situações nas quais há influência da carga subjetiva do intérprete ou de que (ii) os textos são potencialmente vagos.

Essas duas afirmações devem ser minimamente trabalhadas para que possam conviver e apresentar resultados satisfatórios, sob pena de ecletismo estéril.

A flexibilização aparecerá, nesses casos, mais como apaziguadora de um rigor excessivo das escolas como a jurisprudência dos conceitos do que como uma tentativa de conciliação entre relativismo cognitivo (atuação criadora do intérprete, por exemplo) e segurança jurídica.

Por fim, já que a origem e as características básicas da textura aberta dos textos normativos foram tratadas, vale fazer uma última ressalva.

Trata-se da constatação de que, muito embora Waismann tenha buscado inspiração na obra de Wittgenstein para formar sua noção de textura aberta [porosität der Begriffe], o enfoque deste último será diverso, sobretudo com o amadurecimento de suas obras posteriores ao Tractatus e que muitos definem como caracterizadoras de um segundo Wittgenstein.

Apesar de não muito sucinta, essa discussão tem relevante interesse, já que trata da definição dos limites dos conceitos (conceito de conceito) e foi objeto, por exemplo, de uma discussão teórica, na seara jurídica, travada entre Eros Grau e Celso Antonio Bandeira de Mello [2001] acerca da discricionariedade [Grau, 2002a:191-224].

\footnotetext{
13 Uma tentativa nesse sentido aparece em nossa tese, quando fazemos uma análise da interpretação da norma tributária como um processo de concreção normativa e as conseqüências daí advindas [Andrade, 2006].
} 
Esse tema, entretanto, não será tratado aqui, mas, ainda assim, convém assinalar a distinção entre nosso enfoque (wittgensteiniano) e outra forma de se tratar a questão da vagueza dos textos normativos (dos conceitos, enfim).

\section{Fugindo de uma hermenêutica tradicional ${ }^{14}$}

Pois bem, a idéia de que os conceitos devem ter seu limite de aplicação bem definido já era exaustivamente defendida por Frege. ${ }^{15}$

Para Frege e Russel, a vagueza da linguagem natural/ordinária era vista como um defeito a ser evitado (daí a importância da lógica); para Wittgenstein (que concordava com a ambivalência das proposições - estas deveriam apontar ou-não para o real), ${ }^{16}$ entretanto, a vagueza era uma questão justificável e apenas superficial, afinal, a linguagem ordinária estava em boa ordem lógica [TLP:5.5563], bastava a análise lógica, pois toda proposição apresenta uma determinabilidade de sentido, que é a precondição de sua possibilidade de representar o real e ter algum sentido [Glock, 1998:126-127]. ${ }^{17}$

Com a transição do pensamento de Wittgenstein, mantida a noção de que a linguagem ordinária permanecia perfeita, ${ }^{18}$ sua obra começa a refletir a idéia de que a vagueza é uma característica essencial da linguagem (não necessariamente desejável), resistindo à exigência dogmática da determinabilidade de sentido, da necessidade de se eliminar dúvidas ou desacordos.

Da mesma forma, o repercutente termo 'textura aberta', de Waismann, não corresponde a uma rejeição da exatidão, mas sim da exigência de que a inexatidão seja impossível (muito embora ele se baseie aqui em idéias verificacionistas que Wittgenstein repudiara por ocasião das Investigações $[P h U]$. Nem todos os conceitos são realmente vagos, e, embora a maior parte dos conceitos empíricos admita casos fronteiriços, nem por isso se tornam inúteis, uma idéia

\footnotetext{
${ }^{14}$ Aqui abordaremos somente nossa crítica ao uso da noção de textura aberta sem o abandono dos pressupostos de uma hermenêutica tradicional (representacionalista). Sobre nossa visão hermenêutica, ver Andrade [2006], sobretudo [2006:121-189].

${ }^{15}$ Autor esse que propunha a ambivalência das sentenças, ou seja, elas deveriam ser verdadeiras ou falsas. Além disso, Frege tratava os conceitos como funções, nas quais os valores são estipulados inequivocamente para cada argumento. "Para evitar a vagueza, uma definição deve ser completa: deve determinar para cada objeto se cai ou não sob o conceito, quaisquer que sejam os fatos" [Glock, 1998:126].

16 "A realidade deve ser fixada [fixiert sein], por meio da proposição, a um sim ou não". $[\ldots][T L P: 4.023]$.

${ }^{17}$ Os próximos parágrafos seguirão de perto a análise de Glock sobre o verbete "determinabilidade do sentido" [1998:126-128], bem como a obra de Wittgenstein.

18 "It is wrong to say that in philosophy we consider an ideal language as opposed to our ordinary one. For this makes it appear as though we thought we could improve on ordinary language. But ordinary language is all right $[\ldots][B l B: 28$ - original em inglês $]$.
} 
que Hart estendeu aos conceitos legais, com o objetivo de combater o formalismo legal e o ceticismo quanto a regras [Glock, 1998:127].

Em conclusão, pode-se afirmar que a constatação da vagueza das normas jurídicas (textos normativos) não representa, no âmbito de nosso estudo, a proclamação de um ideal verificacionista a atribuir ao intérprete a tarefa de precisar o sentido dos textos jurídicos, o que seria, ao final, estabelecer tão-somente outra pauta hermenêutica nos moldes da tradicional. Algo como: "o aplicador deve percorrer todos os métodos hermenêuticos e, após, precisar os termos vagos", o que não é o caso.

A afirmação de que a linguagem funciona em seu uso cotidiano (as normas são interpretadas - produzem-se normas-decisão) tem muito mais a ver com a atuação humana ("uma parte de uma atividade ou de uma forma de vida" $[P h U: \S 23]^{19}$ do que com a possibilidade de se manter um modelo cognitivo/epistemológico baseado na relação sujeito-objeto e na possibilidade de acesso ao núcleo comunicativo preexistente em cada texto normativo (muitas vezes encoberto por uma névoa de vagueza)).

No fundo, o que está em questão é a não-aceitação da linguagem como representação de objetos ou, indo mais longe, da linguagem como representação semântica.

A primeira (representação de objetos) já foi criticada, inclusive, pela semiótica e pela lingüística estrutural.

Já a segunda (representação semântica) aponta para uma tradição extremamente complexa e arraigada, qual seja, a de se considerar:

[...] a mente enquanto um grande espelho, contendo variadas representações - algumas exatas, outras não - e capaz de ser estudado por meio de métodos puros, não empíricos. Sem a noção da mente como espelho, a noção de conhecimento como exatidão de representação não se teria sugerido. Sem esta última noção, a estratégia comum a Descartes e Kant - obter representações mais exatas ao inspecionar, reparar e polir o espelho, por assim dizer - não teria feito sentido. Sem essa estratégia em mente, afirmações recentes de que a filosofia poderia consistir em "análise conceitual", ou "análise fenomenológica", ou "explicação de significados", ou exame da "lógica de nossa linguagem" ou da "estrutura

\footnotetext{
19 [...] "Das Wort "Sprachspiel" soll hier hervorheben, dass das Sprechen der Spreche ein Teil ist einer Tätigkeit, oder einer Lebensform” [PhU:§23].

Seguir uma regra, fazer uma comunicação, dar uma ordem, jogar uma partida de xadrez são hábitos [Gepflogenheiten] (costumes, instituições).

Compreender uma frase significa compreender uma linguagem. Compreender uma linguagem significa dominar uma técnica $[P h U: \S 199]$. A linguagem é um instrumento. Seus conceitos são instrumentos $[P h U: \S 69$, Pitkin 1984:63].
} 
da atividade constitutiva da consciência" não teriam feito sentido". [Rorty, 1995:27].

Ou ainda:

São as imagens mais que as proposições, as metáforas mais que as afirmações que determinam a maior parte de nossas convicções filosóficas [Rorty, 1995:27].

(...) as palavras tomam seus sentidos antes de outras palavras do que em virtude de seu caráter representativo, [...] os vocabulários adquirem seus privilégios antes dos homens que os usam que de sua transparência para o real [Rorty, 1994:362].

Do ponto de vista epistemológico, fundamentar o acesso do intérprete ao sentido preexistente do texto e às operações mentais inerentes à sua atividade de definição do que o espírito do texto normativo contém, com a finalidade de justificar a extensão do sentido primitivo ao sentido que se pretende como resultado é justamente o tipo de enfoque que buscamos evitar.

O século XX parece ter sido a época marcada pelo abandono de alguns sonhos científicos. Além do desgaste dos positivismos e dos formalismos, um desses sonhos abalados em seus alicerces foi o da determinabilidade do sentido pela lógica.

$\mathrm{Na}$ seara jurídica, a doutrina passou a conviver com a idéia de conceitos indeterminados e cláusulas gerais, sendo quase um lugar comum relatá-los didaticamente, sobretudo após a obra de Engisch [2001].

No âmbito da lógica, todavia, a idéia de que um conceito não possuísse um limite bem definido, que um objeto não fosse eficazmente classificado de acordo com um correspondente conceito, era assustadora.

A própria idéia de fundamentar a lógica a partir da matemática, de forma a construir uma linguagem científica cujos conceitos fossem definíveis (falar uma língua é realizar um cálculo), era o projeto da lógica do início do século XX e, posteriormente, do positivismo do Círculo de Viena (de Frege e Russel até Popper). ${ }^{20}$

Os resultados dessa empresa não foram, do ponto de vista da determinabilidade (exata) do sentido, tão frutíferos, mas aqui se tem, também, um problema sobre qual deve ser o objetivo da exatidão dos conceitos e de sua determinabilidade.

\footnotetext{
${ }^{20}$ Bento Prado Jr [1994:71-72], ao analisar a questão do relativismo (e o combate a ele) na história da filosofia, lembrará de dois pontos máximos desse combate, a saber, o século IV a.C. (com a formação da filosofia grega clássica) e na viragem do século XIX ao XX (com diversas tentativas de devolver à filosofia seu fundamento absoluto). Nesse último caso, o autor comenta que filósofos como E. Husserl, H. Bergson e B. Russel, cada um à sua maneira, buscaram formas de combater o relativismo "(contra o psicologismo, cego para as exigências da fundamentação da lógica, e contra uma epistemologia meio kantiana, meio positivista, que proíbe nosso acesso às coisas em si ou ao absoluto)".
} 
Um ideal menos pretensioso e exigente de determinabilidade pode ser alcançado em contextos específicos de concreção normativa. O enfoque, obviamente, terá que ser deslocado do plano do acesso ao conteúdo preexistente dos termos jurídicos empregados no texto normativo para o de resultados práticos (análise de resultados obtidos - normas-decisão).

Explica-se: Não há que se ter um único ideal de exatidão (os conceitos determinados em detrimento dos indeterminados), já que os conceitos (ao nosso entender, sempre indetermináveis, a partir de premissas essencialistas) atuam em contextos específicos de forma satisfatória.

Não há como se estabelecer, de antemão, as regras de como cada conceito jurídico deva ser interpretado/aplicado. Para que um conceito seja útil, basta que ele seja definido em determinados contextos práticos, pois o emprego das palavras não está totalmente regulamentado por regras $[P h U: \S 68]$. Muitas vezes um conceito de contornos imprecisos é o que foi possível e é o que basta a uma determinada situação [PhU:§ 71].

Deslocando, portanto, a idéia da interpretação do texto normativo e de seus resultados (declarativo, restritivo e extensivo) da determinabilidade do sentido para a de análise da norma-decisão formada, tem-se: ${ }^{21}$

(i) um texto normativo que emprega conceitos cujos significados estão sendo construídos local e temporalmente; (ii) essas construções formam um arcabouço conceitual, um sistema de referências mediado por adestramentos (formação universitária, formação de jurisprudência sobre determinados aspectos de cada conceito); ${ }^{22}$

\footnotetext{
${ }^{21}$ Para uma abordagem mais detida da formação da norma-decisão [Entscheidungsnorm] e a comparação com o vocabulário mais tradicional da hermenêutica (interpretação X integração, interpretação extensiva, restritiva, literal e analógica), ver Andrade [2006], sobretudo [2005:149-161].

${ }^{22}$ A segurança nas relações cognitivas não deriva de fundamentos metódicos, mas, antes, da consistência proporcionada pela forma biológica da espécie e a prática social. É a confluência desses fatores que constitui um sistema de proposições fundacionais.

O ponto mais importante de Sobre a Certeza é desenvolver subsídios para uma epistemologia socializada (idéia que a sociologia alegar ter retomado). O conhecimento de uma determinada cultura ou de qualquer um de seus membros não pode ser apreendida da experiência de um indivíduo. "O conhecimento acumulado de uma cultura é uma conquista coletiva - uma idéia compartilhada por hegelianos, marxistas e pragmatistas". A totalidade desse conhecimento é inacessível, sendo o aprendizado sobre os padrões referenciais uma aceitação da autoridade de uma comunidade. Isso não impede o pensamento crítico, fazer parte de uma comunidade (e de seu sistema referencial) é tomar parte em atividades epistêmicas "que nos permitem retificar algumas de nossas crenças, e, ocasionalmente, até mesmo partes de nossa visão de mundo. Distinguindo-se da epistemologia naturalizada de Quine, a epistemologia socializada de Wittgenstein salienta esse ponto sem reduzir o processo de formação de crenças, bahavioristicamente, a uma questão de estímulos e respostas" [Glock, 1998:78].

É aqui que pensamos que uma teoria socio-biológica [não confunda-se com a teoria de E. O. Wilson] pode trazer subsídios para um pensamento jurídico baseado não mais nas relações cognitivas clássicas (relação entre sujeito e objeto).
} 
(iii) novas normas-decisão podem ser comparadas com as decisões outrora formuladas (ou com as opiniões doutrinárias sobre o tema), o que permitirá relações de proximidade e comparação.

Esses limites sociobiológicos ${ }^{23}$ é que permitirão a crítica a decisões que pareçam ir contra o nosso sistema referencial [Bezugssystem], ir contra aquele jogo de linguagem até então aplicado.

Certos resultados (normas-decisão) freqüentemente frustram o que determinada comunidade entendia como correto, mas, chamar a atenção ao caráter decisório desse processo, é permitir a chance de discussão entre as partes (em sentido amplo) envolvidas no litígio.

São Paulo, fevereiro de 2008.

\section{Referências}

ANDRADE, José Maria Arruda de. Interpretação da norma tributária. São Paulo: MP Editora, 2006.

BIX, Brian. Law, language and legal determinacy. Oxford: Clarendon Press, 1993.

BIX, Brian. Questões na interpretação jurídica. In: Direito e interpretação. São Paulo: Malheiros, 2000. p. 205-232.

\footnotetext{
Sobre arcabouço conceitual e sistema de referências em Wittgenstein e sua aplicação no Direito, ver Andrade [2006:125-141]. Ver Wittgenstein [ $\ddot{U} G]$. Sobre a utilização de teorias biológicas como teorias do conhecimento, ver Andrade [2006:141-149 - "O intérprete como Sistema Autopoiético, e não o Direito"].

“As palavras, como sabemos, são ações, e não coisas que passam de lá para cá. É nossa história de interações recorrentes que nos permite um acoplamento estrutural interpessoal efetivo. Descobrimos que compartilhamos um mundo que especificamos em conjunto por meio de nossas ações. Isso é tão evidente a ponto de nos ser literalmente invisível.” [...]. Maturana \& Varela [1995:251-252].

${ }^{23}$ Esses limites não devem ser confundidos como limites de significação, como novas pautas para se elaborar uma nova teoria da interpretação baseada no acesso a significados preexistentes. A luta contra o essencialismo e o representacionalismo é uma eterna vigilância, pois, devido ao nosso adestramento, facilmente podemos cair em tentações de enfoques semânticos ou mentalistas.

Não à toa, Richard Rorty, ao comentar essa tática anti-representacionalista, assinala a facilidade em voltar ao mesmo enfoque:

“[...] Portanto, nem mesmo dizendo que o homem é tanto sujeito como objeto, pour-soi tanto como en-soi, estamos apreendendo nossa essência. Não escapamos ao platonismo dizendo que 'nossa essência é não ter essência', se então tentamos usar essa percepção como base para uma tentativa construtiva e sistemática de descobrir verdades ulteriores sobre os seres humanos" [Rorty, 1994:371].

No mesmo sentido, Wittgenstein declara: "Eu queria dizer que é notável que aqueles que apenas atribuem realidade às coisas e não às nossa representações mentais se movimentam tão naturalmente no mundo das representações e nunca sintam a falta de sair dele" [TBT:30].
} 
BOBBIO, Norberto. O positivismo jurídico: lições de filosofia do direito. Tradução de Márcio Pugliesi, Edson Bini, Carlos E. Rodrigues. São Paulo: Ícone Ed, 1995.

CARRIÓ, Genaro R. Notas sobre derecho y lenguaje. 2. ed. Buenos Aires: Abeledo Perrot, 1979.

ENGISCH, Karl. Introdução ao pensamento jurídico. 8. ed. Tradução de João Baptista Machado. Lisboa: F. Calouste Gulbenkian, 2001.

GLOCK, Hans-Johann. Dicionário Wittgenstein. Tradução de Helena Martins. Rio de Janeiro: Jorge Zahar Editor, 1998.

GRANGER, Gilles-Gaston. Círculo de Viena. In: Filosofia Analítica. Lisboa: Gradiva, s.d. p. 8386.

GRANGER, Gilles-Gaston. Neopositivismo. In: Filosofia Analítica. Lisboa: Gradiva, s.d. p. 87-96. Grau, Eros Roberto. Ensaio e discurso sobre a interpretação/aplicação do direito. São Paulo: Malheiros, 2002.

GRAU, Eros Roberto. O direito posto e o direito pressuposto. 4. ed. São Paulo: Malheiros, 2002.

HALLER, Rudolf. Wittgenstein e a filosofia austríaca: questões. São Paulo: EDUSP, 1990.

HART, Herbert. O conceito de direito. Lisboa: F. Calouste Gulbenkian, 1986.

KELSEN, Hans. Teoria pura do direito. 6. ed. Tradução de João Baptista Machado. Coimbra: Armênio Amado Editor, 1984.

MATURANA, H.; VARELA, F. A árvore do conhecimento. Campinas: Editorial Psy, 1995.

MELLO, Celso Bandeira de. Discricionariedade e controle jurisdicional. 2. ed., 5. tir. São Paulo: Malheiros, 2001.

MONK, Ray. Wittgenstein: o dever do gênio, trad. Carlos Afonso Malferrari. São Paulo: Companhia das Letras, 1995.

MÜLLER, Friedrich. Métodos de trabalho do direito constitucional. 2. ed. Tradução de Peter Naumann. São Paulo: Max Limonad, 2000.

NINO, Carlos Santiago. Introducción al análisis del derecho. Barcelona: Editorial, 1999.

PITKIN, Hanna Fenichel. Wittgenstein: el lenguaje, la politica y la justicia - sobre el significado de Ludwig Wittgenstein para el pensamiento social y político. Madrid: Centro de Estudios Constitucionales, 1984.

PRADO JR., Bento . (1994) O relativismo como contraponto. In: CICERO Antonio; SALOMÃO Waly (Orgs.). O relativismo enquanto visão do mundo. São Paulo: Ed. Francisco Alves, 1994. p. 7194.

RORTY, Richard. A filosofia e o espelho da natureza. Rio de Janeiro: Relume Dumará, 1995. 
RORTY, Richard. Contingência, ironia e solidariedade. Lisboa: Edorial Presença, 1994.

Struchiner, Noel. Direito e linguagem: uma análise da textura aberta da linguagem e sua aplicação ao direito. Rio de Janeiro: Renovar, 2002.

WITTGENSTEIN, Ludwig. Philophische Untersuchungen. In: Werkausgabe. Tradução bilíngüe espanhola Investigaciones Filosóficas - Alfonso García a Suárez e Ulises Moulines. Barcelona: Editorial Crítica, 1988. v. 1.; Traduão portuguesa, Investigações Filosóficas. 2. ed. Lisboa: Calouste Gulbenkian, 1995; Tradução brasileira de José Carlos Bruni In: Os Pensadores. 2. ed. São Paulo: Ed. Abril, 1979.

WITTGENSTEIN, Ludwig. The Big Typescript (MS213). Revue Internationale de Philosophie, v. 43, n. 169, p. 175-203, trad. port. "Filosofia”, António Zilhão, in Manuscrito - Revista Internacional de Filosofia, Vol. XVIII - n. 2. Campinas: Centro de Lógica, Epistemologia e História da Ciência, Unicamp, p. 1-37.

WITTGENSTEIN, Ludwig. The Blue Book. New York: Harper \& Row, 1965.

WITTGEnSteIN, Ludwig. Tractatus Logico-Philosophicus. Tradução brasileira bilingue Luiz Henrique Lopes dos Santos. São Paulo: EDUSP, 1994.

WITTGENSTEIN, Ludwig. Über Gewissheit. Tradução portuguesa bilíngue Da Certeza, Maria Elisa Costa. Lisboa: Edições 70, 1998. 